\title{
Relationship between IGF-I Concentration and Metabolic Profile in Children with Growth Hormone Deficiency: The Influence of Children's Nutritional State as well as the Ghrelin, Leptin, Adiponectin, and Resistin Serum Concentrations
}

\author{
Renata Stawerska, ${ }^{1}$ Joanna Smyczyńska, ${ }^{1}$ Maciej Hilczer, ${ }^{1,2}$ and Andrzej Lewiński ${ }^{1,3}$ \\ ${ }^{1}$ Department of Endocrinology and Metabolic Diseases, Polish Mother's Memorial Hospital-Research Institute, Rzgowska Street \\ 281/289, 93-338 Lodz, Poland \\ ${ }^{2}$ Department of Pediatric Endocrinology, Medical University of Lodz, Rzgowska Street 281/289, 93-338 Lodz, Poland \\ ${ }^{3}$ Department of Endocrinology and Metabolic Diseases, Medical University of Lodz, Rzgowska Street 281/289, 93-338 Lodz, Poland
}

Correspondence should be addressed to Andrzej Lewiński; alewin@csk.umed.lodz.pl

Received 22 February 2017; Accepted 13 April 2017; Published 17 May 2017

Academic Editor: Riccarda Granata

Copyright (C) 2017 Renata Stawerska et al. This is an open access article distributed under the Creative Commons Attribution License, which permits unrestricted use, distribution, and reproduction in any medium, provided the original work is properly cited.

\begin{abstract}
Background. Some, however not all, children with growth hormone deficiency (GHD) reveal a tendency towards metabolic disorders. Insulin-like growth factor I (IGF-I) is the main mediator of GH anabolic effects. Objective. The aim of the study was to compare ghrelin, adiponectin, leptin, resistin, lipid, glucose, and insulin concentrations in GHD children, depending on the IGF-I bioavailability. Methods. The analysis comprised 26 children with GHD, aged 5.7-15.3 yrs. Fasting serum concentrations of IGF-I, IGFBP-3, ghrelin, leptin, adiponectin, resistin, lipids, glucose, and insulin were measured. The GHD children were divided into two subgroups: (1) with lower IGF-I/IGFBP-3 molar ratio and (2) with higher IGF-I/IGFBP-3 molar ratio. The control group consisted of 39 healthy children, aged 5.1-16.6 yrs, of normal height and body mass. Results. GHD children with lower IGF-I/IGFBP-3 molar ratio were found to have a significantly lower body mass and insulin and triglyceride concentrations, as well as significantly higher ghrelin and adiponectin concentrations than GHD children with higher IGF-I/ IGFBP-3. Conclusions. A better metabolic profile characterised GHD children with low IGF-I bioavailability. This phenomenon may be the result of high adiponectin and ghrelin concentrations in those children and their influence on adipose tissue, glucose uptake, and orexigenic axis.
\end{abstract}

\section{Introduction}

It is well known that growth hormone $(\mathrm{GH})$ promotes linear growth during childhood. However, GH also displays considerable metabolic activity: it stimulates lipolysis with an elevation of circulating free fatty acids, as well as promotes gluconeogenesis and reduces peripheral glucose uptake, which is the reason of relative insulin resistance $[1,2]$. Thus, adult patients with isolated GH deficiency (GHD) display unfavourable lipid profile with increased fat mass, as well as increased insulin secretion, though with good insulin sensitivity [1, 3]. However, not all children with GHD show a tendency towards metabolic disorders [4-8].

The main peripheral mediator of GH activity is IGF-I, and GHD is defined as the secondary IGF-I deficiency. It should be noted that-besides the low IGF-I serum concentration-an important role is played by the decreased IGF-I bioavailability. Both the IGF-I bioavailability and the stability of its concentration are determined by binding to specific proteins, especially IGFBP-3. The IGF-I/IGFBP3 molar ratio is considered to be the IGF-I bioavailability index [9]. 
Recently, we have observed a negative correlation between IGF-I/IGFBP-3 molar ratio and ghrelin concentration in short stature children [10]. Thus, we have suggested that the lower bioavailability of IGF-I is a stimulating factor for the ghrelin synthesis in a compensatory mechanism. We also proved that ghrelin concentrations were significantly higher in children with GHD when compared to children with idiopathic short stature (ISS) and to children with normal height [11]. Ghrelin-the peptide hormone produced in the stomach-is a natural endogenous ligand for the GH secretagogue receptor [12]. In addition to its role as a stimulator of $\mathrm{GH}$ release, it is the most potent known endogenous orexigenic peptide that regulates appetite and body weight $[13,14]$. Ghrelin reduces lipolysis, and it directly promotes weight gain, fat accumulation, and adipogenesis, mainly in a GH-independent way [15]. Moreover, it reduces insulin secretion and induces hyperglycaemia [16].

Futhermore, an important target for GH and IGF-I action is adipose tissue. Adipocytokines produced by adipose tissues, such as leptin, adiponectin, and resistin, are also significant factors in regulating fatty acid metabolism, as well as insulin secretion and sensitivity.

Leptin is strongly correlated with the body mass [17], and at the level of the hypothalamus, it inhibits the appetite; thus, its action is opposed to ghrelin action [18]. Leptin also increases hepatic gluconeogenesis and muscle fatty acid oxidation [19]. Moreover, it plays atherogenic, prothrombotic, and angiogenic roles by stimulating vascular inflammation, oxidative stress, and smooth muscle hypertrophy, contributing to pathomechanism of hypertension and atherosclerosis [20]. In children with GHD, the results of leptin concentrations are divergent $[7,8,21]$.

It is thought that adiponectin, similar to GHRH, induces $\mathrm{GH}$ secretion, and the high adiponectin levels in a model of $\mathrm{GHRH}$ resistance are described as a compensatory mechanism to the lack of GHRH action [22]. Adiponectin stimulates uptake and glucose utilization, as well as fatty acid oxidation while it inhibits gluconeogenesis [23]. The effect is a reduction of free fatty acid and triglyceride concentrations and an increase in insulin sensitivity, manifested by a decrease in blood glucose levels without increasing insulin levels [20, 23].

Resistin is known to be a mediator of GH-modulated insulin sensitivity, and in untreated GHD children, higher resistin levels have been observed [24]. It is likely that resistin is linked to obesity and insulin resistance [8].

In the present study, we have decided to analyse the metabolic profile (insulin resistance and lipids) in two untreated groups of GHD patients: (1) with lower (worse) IGF-I bioavailability and (2) with higher (better) IGF-I bioavailability, and we have tried to evaluate the additional role of nutritional state, as well as ghrelin, leptin, adiponectin, and resistin on metabolic profile in these groups.

\section{Materials and Methods}

The study group consisted of 26 short children (11 girls and 15 boys) aged 5.7 to 15.3 yrs (the mean age \pm SD: $10.91 \pm 2.55$ years) in whom isolated GHD was diagnosed, based on the following criteria:

(1) Height standard deviation score (HSDS) below -2.0 from the mean value for child's age and sex [25] (children's height was measured using a stadiometer)

(2) Low height velocity below $-1.0 \mathrm{SD}$ from the mean value for child's age and sex

(3) Excluding genetic reasons of the short stature (i.e., Turner's syndrome, Prader-Willi syndrome)

(4) Excluding untreated hypothyroidism, chronic diseases, or undiagnosed gastrointestinal tract complaints

(5) Decreased $\mathrm{GH}$ secretion: $\mathrm{GH}_{\max }$ values below $10 \mathrm{ng} / \mathrm{ml}$ during a 3-hour nocturnal profile and during two stimulation tests: the first one, after clonidine administered orally (with the dose of $0.15 \mathrm{mg} / \mathrm{m}^{2}$ of the body surface) and $\mathrm{GH}$ concentration measurements at time 0 and at 30th, 60th, 90th, and 120th minutes of the test and the second one, after intramuscular administration of glucagon (in the dose of $30 \mu \mathrm{g} / \mathrm{kg}$ of body weight, not exceeding $1 \mathrm{mg}$ ), with $\mathrm{GH}$ concentration measurements at time 0 and at 90th, 120th, 150th, and 180th minutes

(6) Normal concentration of other pituitary hormone secretion-excluding multiple hormonal pituitary deficiency (MPHD)

(7) Normal results of MR images of the hypothalamicpituitary region.

In all the children, on the faith of the child's current position on percentile charts, the height age (HA) was calculated (as the age ascribed to the 50th percentile for a given child's height). The body mass was assessed in all patients and that was followed by calculation of the body mass index standard deviation score for chronological age (BMI SDS for CA) and for height age (BMI SDS for HA). The stage of puberty was assessed in each child by Tanner's scale. In all the children, we confirmed the Tanner I (prepubertal) stage. It was related to the delayed bone age (which was assessed based on X-rays of nondominant hand and wrist, according to GreulichPyle's standards): below 11 years in girls and below 12 years in boys in each of our GHD child, and, in consequence, the delay of biological development).

Moreover, fasting serum concentrations of total ghrelin, leptin, adiponectin, resistin, lipids, glucose, and insulin, as well as IGF-I and IGFBP-3 were measured. IGF-I concentrations were also expressed by IGF-I SDS, according to the reference data [26].

For the calculation of IGF-I/IGFBP-3 molar ratio, the following molecular masses were used: $7.5 \mathrm{kDa}$ for IGF-I and $42.0 \mathrm{kDa}$ for IGFBP-3. For IGF-I/IGFBP-3 molar ratio, the cutoff point was established at the median values.

According to the results, the group of GHD children was divided into two subgroups: GHD children with low IGF-I 
bioavailability ( $n=13$; IGF-I/IGFBP-3 molar ratio below the cutoff level) and with normal IGF-I bioavailability $(n=13$; IGF-I/IGFBP-3 molar ratio equal or higher than the cutoff point). Based on the results of fasting glucose and insulin concentration, the insulin resistance (IR) index (IRI) HOMA was calculated [27].

The control group consisted of 39 healthy children (12 girls and 27 boys), aged 5.1 to 16.6 years (mean \pm SD: 10.87 \pm 3.12 years), with normal body height and normal body weight. In that group of children, fasting total ghrelin, leptin, adiponectin, resistin, lipids, glucose, and insulin, as well as IGF-I and IGFBP-3 concentrations were assessed.

Growth hormone levels were measured using the immunometric method. The measurements were performed by Immulite, DPC assay kits, calibrated to the WHO IRP 98/574 standard set of the following sensitivity level: $0.01 \mathrm{ng} / \mathrm{ml}$, range: up to $40 \mathrm{ng} / \mathrm{ml}$, conversion index: $\mathrm{ng} / \mathrm{ml} \times 2.6=\mathrm{mIU} / \mathrm{l}$, the intra-assay $\mathrm{CV}: 5.3-6.5 \%$, and interassay CV: $5.5-6.2 \%$.

Both IGF-I and IGFBP-3 concentrations were assessed by the Immulite, DPC assays; WHO NIBSC 1st IRR $87 / 518$ standard was applied, with the analytical sensitivity of $20 \mathrm{ng} / \mathrm{ml}$, calibration range up to $1600 \mathrm{ng} / \mathrm{ml}$, the intraassay CV: $3.1-4.3 \%$, and interassay CV: $5.8-8.4 \%$. The assay for IGFBP-3 assessment was calibrated to WHO NIBSC Reagent 93/560 standard, with analytical sensitivity $0.02 \mu \mathrm{g} / \mathrm{ml}$, the calibration range up to $426 \mu \mathrm{g} / \mathrm{ml}$, the intra-assay CV: $3.5-5.6 \%$, and the total CV: $7.5-9.9 \%$.

The total ghrelin concentration was measured using the radioimmunometric method with Millipore assay kits of the following sensitivity level: $100-10.000 \mathrm{pg} / \mathrm{ml}$, the intra-assay CV: $3.3-10.0 \%$, and interassay CV: $14.7-17.8 \%$.

The leptin, resistin, and adiponectin concentrations were measured using the Millipore ELISA kit (Linco Research). The sensitivity level, intra-assay CV, and interassay CV were as follows: $0.5-100 \mathrm{ng} / \mathrm{ml}, 1.4-4.9 \%$, and $1.3-8.6 \%$ for leptin; from $0.16 \mathrm{ng} / \mathrm{ml}, 3.2-7.0 \%$, and $7.1-7.7 \%$ for resistin; and from $0.78 \mathrm{ng} / \mathrm{ml}, 7.4 \%$, and $2.4-8.4 \%$ for adiponectin, respectively.

Plasma insulin concentration was measured using the DRG ELISA kit; sensitivity level $1.76-100 \mu \mathrm{IU} / \mathrm{ml}$, the intra-assay CV: $1.8-2.6$, and interassay CV: 2.9-6.0. Plasma glucose concentration was determined with the enzymatic method, with the use of hexokinase.

Shapiro-Wilk's test was used to assess the distribution of the variables. A chi-square test and a one-way ANOVA were applied for statistical analysis, with the subsequent use of a post hoc test, in order to statistically assess differences between individual pairs of groups. Correlations were evaluated using Pearson's test. Statistically significant differences were accepted when $p$ value was below 0.05 .

\section{Results}

First, the data of the GHD group and of the control group were analysed (Table 1). It was not surprising that the children with GHD were significantly shorter (see HSDS values) and heavier (see BMI SDS for HA values) than children from the controls.
In the group of children with GHD, significantly higher levels of ghrelin from the controls $(1352.03 \pm 715.75$ versus $1064.10 \pm 493.39 \mathrm{pg} / \mathrm{ml})$ and leptin $(13.09 \pm 11.72$ versus $7.74 \pm 9.14 \mathrm{ng} / \mathrm{ml})$ but lower levels of resistin $(9.44$ \pm 2.90 versus $12.68 \pm 6.33 \mathrm{ng} / \mathrm{ml}$ ) were recorded. The adiponectin concentrations were similar in both groups. Significantly higher concentrations of triglycerides $(84.71 \pm 34.17$ versus $63.47 \pm 26.64 \mathrm{mg} / \mathrm{dl}$ ) in GHD than in the controls were observed, whereas there was no difference between the groups as regards the concentrations of cholesterol and its fractions. Fasting glucose and insulin concentrations, as well as IRI HOMA did not differ between the groups.

We found that IGF-I SDS value was not correlated with any of the analysed parameters in the studied group of children (GHD and controls together, data not shown), while IGF-I/IGFBP-3 molar ratio was negatively correlated with ghrelin $(r=-0.35, p<0.05)$ and positively with triglycerides $(r=+0.4, p<0.05)$ and insulin $(r=+0.41, p<0.05)$ concentrations, as well as with IRI HOMA $(r=+0.36$, $p<0.05)$ (Table 2). In turn, among children with GHD, we confirmed a negative correlation between the IGF-I/IGFBP3 molar ratio and both ghrelin $(r=-0.34, p<0.05)$ and adiponectin $(r=-0.41, p<0.05)$ and a positive one between IGF-I/IGFBP-3 molar ratio and both insulin $(r=+0.48$, $p<0.05)$ and IRI HOMA $(r=+0.41, p<0.05)$. Also, we observed a negative correlation between IGF-I/IGFBP-3 molar ratio and HDL-cholesterol concentration in GHD children $(r=-0.59, p<0.05)$ (Table 2).

Thus, the GHD children-according to values of IGF-I/ IGFBP-3 molar ratio-were divided into two subgroups: lower IGF-I bioavailability and higher IGF-I bioavailability (see Materials and Methods).

It was found that the children from GHD-lower-IGF-I bioavailability group were significantly slimmer (even after correction of BMI SDS values for HA) than the children from GHD-higher-IGF-I bioavailability group. The concentrations of cholesterol and its fractions did not differ between groups. Furthermore, we observed a significantly lower triglyceride $(68.14 \pm 28.34$ versus $96.30 \pm 34.32 \mathrm{mg} / \mathrm{dl})$ and insulin $(5.92 \pm 4.43$ versus $9.07 \pm 3.63 \mathrm{uIU} / \mathrm{ml})$ concentrations, as well as IRI HOMA $(1.36 \pm 1.04$ versus 1.93 $\pm 0.94)$ in the GHD group with lower IGF-I bioavailability than in the GHD group with higher IGF-I bioavailability. Also, significantly higher ghrelin $(1648.95 \pm 657.60$ versus $1005.64 \pm 640.44 \mathrm{pg} / \mathrm{ml})$ and adiponectin $(23.72 \pm 6.3$ versus $15.06 \pm 6.18 \mathrm{ng} / \mathrm{ml}$ ) concentrations in the group with lower IGF-I bioavailability than in the group with higher IGF-I bioavailability were observed. In turn, both leptin and resistin levels were lower in children with lower IGF-I bioavailability than in those with higher IGF-I bioavailability; however, the differences did not reach a border of statistical significance (Table 3).

The maximal GH secretion during stimulation test after clonidine administration and during nocturnal profile was similar in both groups. Interestingly, we observed a significantly lower maximal concentration of GH during stimulation test after glucagon administration in the lower IGF-I bioavailability than in the higher IGF-I bioavailability group $(4.50 \pm 1.56$ versus $7.33 \pm 2.85 \mathrm{ng} / \mathrm{ml})$ (Table 3$)$. 
TABLE 1: Auxological data and hormonal test results in GHD children and in controls.

\begin{tabular}{|c|c|c|}
\hline Group & GHD & Controls \\
\hline Number of children (girls/boys) & $26(11 / 15)$ & $39(12 / 27)$ \\
\hline Chronological age (years) & $10.91 \pm 2.55$ & $10.87 \pm 3.12$ \\
\hline Height SDS & $-2.53 \pm 0.56^{\mathrm{a}}$ & $-0.58 \pm 1.11^{\mathrm{a}}$ \\
\hline BMI $\left(\mathrm{kg} / \mathrm{m}^{2}\right)$ & $18.51 \pm 3.64$ & $18.23 \pm 3.51$ \\
\hline BMI SDS for CA & $0.37 \pm 1.47$ & $0.15 \pm 1.12$ \\
\hline BMI SDS for HA & $0.94 \pm 1.70^{\mathrm{b}}$ & $0.31 \pm 1.14^{\mathrm{b}}$ \\
\hline IGF-I (ng/ml) & $184.18 \pm 85.61$ & $208.13 \pm 123.77$ \\
\hline IGF-I SDS & $-1.21 \pm 0.90^{\mathrm{b}}$ & $-0.29 \pm 1.03^{\mathrm{b}}$ \\
\hline IGFBP-3 $(\mu \mathrm{g} / \mathrm{ml})$ & $4.49 \pm 1.28$ & $4.65 \pm 1.10$ \\
\hline IGF-I/IGFBP-3 molar ratio & $0.25 \pm 0.12$ & $0.24 \pm 0.14$ \\
\hline Ghrelin (pg/ml) & $1352.03 \pm 715.75^{\mathrm{b}}$ & $1064.10 \pm 493.39^{\mathrm{b}}$ \\
\hline Leptin (ng/ml) & $13.09 \pm 11.72^{b}$ & $7.74 \pm 9.14^{\mathrm{b}}$ \\
\hline Adiponectin (ng/ml) & $19.18 \pm 12.58$ & $17.71 \pm 8.12$ \\
\hline Resistin (ng/ml) & $9.44 \pm 2.90^{\mathrm{b}}$ & $12.68 \pm 6.33^{\mathrm{b}}$ \\
\hline Triglycerides (mg/dl) & $84.71 \pm 34.17^{\mathrm{b}}$ & $63.47 \pm 26.64^{\mathrm{b}}$ \\
\hline Total cholesterol (mg/dl) & $171.70 \pm 33.91$ & $162.00 \pm 31.60$ \\
\hline LDL cholesterol (mg/dl) & $96.63 \pm 31.43$ & $86.79 \pm 23.96$ \\
\hline HDL cholesterol (mg/dl) & $60.19 \pm 14.21$ & $62.84 \pm 15.65$ \\
\hline Glucose $0^{\prime}(\mathrm{mg} / \mathrm{dl})$ & $84.29 \pm 8.01$ & $85.10 \pm 6.24$ \\
\hline Insulin $0^{\prime}(\mathrm{uIU} / \mathrm{ml})$ & $7.67 \pm 4.20$ & $6.93 \pm 4.16$ \\
\hline IRI HOMA & $1.70 \pm 0.99$ & $1.47 \pm 0.93$ \\
\hline
\end{tabular}

Data are presented as the means \pm SD. GHD: growth hormone deficiency; SDS: standard deviation score; BMI: body mass index; CA: chronological age; HA: height age; IGF-I: insulin-like growth factor I; IGFBP-3: insulin-like growth factor binding protein 3; LDL-cholesterol: low density lipoprotein-cholesterol; HDL-cholesterol: high density lipoprotein-cholesterol; IRI HOMA: insulin resistance index according to homeostasis model assessment. In the individual rows of the table, the variables designated with the same letters differ significantly from each other with ${ }^{\mathrm{a}} p<0.00000$ and ${ }^{\mathrm{b}} p<0.05$. One-way analysis of variance (ANOVA) was used for group comparison.

\section{Discussion}

The results of our study showed that the GHD children group was not homogeneous as regards the metabolic profile, nutritional state, and IGF-I bioavailability. On the one hand, it included children with GHD of both the pituitary and hypothalamic origins with different etiology; on the other, it is well known that IGF-I concentration depends not only on GH secretion but also on the nutritional status of children (which in turn is conditioned by many different factors). Moreover, concentrations of certain neuropeptides (i.e., ghrelin, leptin, and insulin) also affect IGF-I level [9, 10, 21].

In our study, the worse metabolic profile characterised those with bigger body mass and higher IGF-I bioavailability and lower ghrelin and adiponectin concentrations. It is not clear what is the cause and what is the effect of disturbances.

It is well known that adult patients with GHD show a tendency towards metabolic disorders (higher body mass, unfavourable lipids, and increased leptin and insulin concentrations) and that they return to normal levels following $\mathrm{GH}$ treatment $[28,29]$. However, the metabolic profile of untreated children with GHD varies in individual reports [4-8]. In Gleeson et al.'s study [4], the lipid profile was disturbed at baseline in GHD children, while abnormal body composition was only observed in older subjects in late puberty. Also, Capalbo et al. reported [5] higher waist to hip ratio, triglycerides, total cholesterol, LDL-cholesterol, and leptin in GHD children compared to controls, whereas no differences in adiponectin concentration were found. Next, Ciresi et al. [6] observed that total and LDL cholesterol were higher in GHD children than in controls, whereas HDL cholesterol, triglycerides, insulin, HOMA-IR, leptin, and adiponectin were similar. López-Siguero et al. [7] confirmed that adiponectin concentration was markedly elevated in GHD children when compared to controls. Similar observations were presented by Meazza et al. [8]. In the group of GHD children analysed by these authors, higher concentrations of both adiponectin and resistin were observed. It should be stressed that there are no unequivocal results in the studies of the aforesaid authors indicating that children with GHD are thicker than those of the control group $[5,6]$, and therefore, excessive body weight is not a permanent feature of GHD in children.

Our results for the whole group of children with GHD are not fully consistent with the results obtained by the authors mentioned above. We decided to test the hypothesis that differences in the metabolic profile in GHD children observed by different groups of researchers might depend on the IGF-I bioavailability and, in consequence, altered compensatory synthesis of these hormones which play an important role in glucose and lipid metabolism (i.e., ghrelin, adiponectin, resistin, and leptin).

Analysing our results, we found worse metabolic profile (higher BMI, higher triglycerides and insulin concentrations, 
TABLE 2: Correlation coefficients between IGF-I/IGFBP-3 molar ratio and individual analysed parameters in the total group of children and separately in the GHD group.

\begin{tabular}{lcc}
\hline $\begin{array}{l}\text { Correlation between IGF-I/ } \\
\text { IGFBP-3 molar ratio and } \\
\text { the following items }\end{array}$ & $\begin{array}{c}\text { Total group } \\
\text { (GHD and controls) }\end{array}$ & GHD group \\
\hline Height SDS & +0.01 & +0.16 \\
BMI SDS for HA & +0.26 & +0.24 \\
Ghrelin & $-0.35^{*}$ & $-0.34^{*}$ \\
Leptin & +0.29 & +0.34 \\
Adiponectin & -0.15 & $-0.41^{*}$ \\
Resistin & -0.24 & 0.0 \\
Triglycerides & $+0.4^{*}$ & $+0.59^{*}$ \\
Cholesterol & +0.22 & +0.05 \\
LDL-cholesterol & +0.16 & +0.08 \\
HDL-cholesterol & -0.04 & $-0.59^{*}$ \\
Glucose & +0.18 & +0.2 \\
Insulin & $+0.41^{*}$ & $+0.48^{*}$ \\
IRI HOMA & $+0.36^{*}$ & $+0.41^{*}$ \\
\hline
\end{tabular}

In the individual rows of the table, the correlation coefficients designated with the asterisks differ significantly from each other.

and higher IRI HOMA) in GHD children with higher IGF-I bioavailability than in GHD children with lower IGF-I bioavailability. The explanation of this phenomenon is not fully clear. It seemed to us that those individuals with GHD who have the lowest bioavailability of IGF-I should present the most severe GHD symptoms. In adults with GHD, strong negative correlations between GH peak concentration and visceral adiposity index (VAI), as well as between IGF-I level and VAI have been proved [29]. VAI takes into account such parameters as BMI and waist circumference, as well as both triglyceride and HDL-cholesterol concentrations. It is a reliable marker for adipose tissue function and distribution. However, generally in children, the correlation between GH peak and IGF-I concentrations is not as obvious as in adults $[10,30]$.

It is generally accepted that IGF-I is a crucial value for promoting the anabolic effects of GH. However, it should be noted that the diagnostic schedule of GHD deficiency is based on the results of GH-stimulating tests, and in some children with GHD, the IGF-I concentrations were within the reference range. Although IGF-I concentration has widely been used for monitoring GH dosing, it is still not an optimal marker for the diagnosis of GHD [31]. The mechanisms by which GH regulates substrate metabolism are not fully understood; perhaps, some of them occur indirectly through IGF-I or antagonism of insulin action [2].

We have taken into consideration the possibility that in the group of GHD children with better IGF-I bioavailability, the unfavourable metabolic profile (higher triglycerides and insulin concentrations) may be related to higher body mass, which has been observed in that group of children. However, some aspects of this issue should also be discussed. First, although children in the group with lower IGF-I bioavailability were significantly slimmer, we did not find any correlation between IGF-I concentration (also IGF-I SDS and IGF-I/
IGFBP-3 molar ratio) and BMI SDS in our group of GHD children. Second, it is well known that in children with obesity, lower GH secretion during stimulating tests in comparison to health population are observed $[32,33]$. This effect is probably the result of somatostatin hypersecretion and decreased ghrelin production [34], as well as hyperinsulinism and elevated concentrations of free fatty acids [32]. Although separate reference data for GH response to most provocative stimuli in obesity are not available, some authors propose to define BMI-specific cutoff points for GHD-diagnosing tests $[35,36]$. However, in the group of children analysed by us, we did not have any child with BMI higher than 2.0 SDS. Furthermore, one of the qualification criteria into the GHD group was too slow height velocity, which was not observed in children with simple obesity related to hyperalimentation. Thus, the suspicion that children from the group of GHD-higher-IGF-I bioavailability were chosen incorrectly, due to false-negative GH-stimulating tests results, does not seem justified.

Among the GHD group, the children with better, as well as with worse nutritional state were identified. Thus, it is possible that in the GHD children with better IGF-I bioavailability and greater body mass, the metabolic profile typical for adult GHD is observed. In turn, in the GHD children with low IGF-I bioavailability and lower body mass, their thinness (for various reasons: silent gastrointestinal diseases, decreased level of neuropeptide-stimulating orexigenic axis, and children with failure to thrive) is accompanied by GHD (and is superimposed on GHD), which results in even more reduced IGF-I production. However, in these cases, the higher adiponectin concentrations were recorded. Perhaps, it was the reason that in that group, a much better metabolic profile was presented (atypical for classic GHD).

It should also be emphasized that children with chronic diseases and those with undiagnosed gastrointestinal tract complaints were excluded from the study group. This eliminates other GHD causes of secondary IGF-I deficiency, especially those observed in children with malnutrition.

The analysis of our data showed that in GHD children with low IGF-I bioavailability, the ghrelin and adiponectin concentrations were significantly higher than in GHD children with higher (better) IGF-I bioavailability. We had reported a higher ghrelin concentration in GHD than in controls in our earlier work [11] and the negative correlation between ghrelin and IGF-I/IGFBP-3 molar ratio [10]. Indeed, a higher ghrelin concentration was observed only in those children with GHD in whom low IGF-I bioavailability was confirmed. In the group of GHD children with better IGF-I bioavailability, the ghrelin concentrations were similar to controls. It is known that both GH and ghrelin are hormones exerting a significant effect on the adipose tissue metabolism but they act differently: GH stimulates lipolysis and reduces the fat accumulation, while ghrelin decreases lipolysis and metabolism which implies that ghrelin can induce an increase in adipose tissue and weight gain [37]. According to the studies of other authors, GH causes relative insulin resistance by reduced peripheral glucose uptake, while ghrelin reduces glucose-stimulated insulin secretion, leading to the deterioration of glucose tolerance $[1,16,38,39]$. 
TABLE 3: Auxological data and hormonal tests results in GHD children with lower IGF-I bioavailability and in GHD children with higher IGF-I bioavailability.

\begin{tabular}{|c|c|c|}
\hline & GHD children with lower IGF-I bioavailability & GHD children with higher IGF-I bioavailability \\
\hline Number of children (girls/boys) & $14(6 / 8)$ & $12(5 / 7)$ \\
\hline Chronological age (years) & $10.24 \pm 2.37$ & $11.99 \pm 2.42$ \\
\hline Height SDS & $-2.42 \pm 0.48$ & $-2.66 \pm 0.63$ \\
\hline BMI $\left(\mathrm{kg} / \mathrm{m}^{2}\right)$ & $16.54 \pm 2.53^{\mathrm{b}}$ & $20.65 \pm 3.51^{\mathrm{b}}$ \\
\hline BMI SDS for CA & $-0.21 \pm 1.43^{\mathrm{d}}$ & $0.99 \pm 1.31^{\mathrm{d}}$ \\
\hline BMI SDS for HA & $0.13 \pm 1.44^{\mathrm{c}}$ & $1.81 \pm 1.55^{\mathrm{c}}$ \\
\hline $\mathrm{GH}_{\max }$ after clonidine (ng/ml) & $7.06 \pm 1.88$ & $7.64 \pm 1.80$ \\
\hline $\mathrm{GH}_{\max }$ after glucagon (ng/ml) & $4.50 \pm 1.56^{\mathrm{d}}$ & $7.33 \pm 2.85^{\mathrm{d}}$ \\
\hline $\mathrm{GH}_{\max }$ during nocturnal profile & $8.83 \pm 5.41$ & $7.34 \pm 3.53$ \\
\hline IGF-I (ng/ml) & $133.33 \pm 54.22^{\mathrm{a}}$ & $243.50 \pm 77.79^{\mathrm{a}}$ \\
\hline IGF-I SDS & $-1.79 \pm 0.63^{\mathrm{b}}$ & $-0.67 \pm 0.79^{\mathrm{b}}$ \\
\hline IGFBP-3 $(\mu \mathrm{g} / \mathrm{ml})$ & $4.46 \pm 1.17$ & $4.52 \pm 1.42$ \\
\hline IGF-I/IGFBP-3 molar ratio & $0.16 \pm 0.07^{\mathrm{b}}$ & $0.32 \pm 0.11^{\mathrm{b}}$ \\
\hline Triglicerides (mg/dl) & $68.14 \pm 28.34^{\mathrm{d}}$ & $96.30 \pm 34.32^{\mathrm{d}}$ \\
\hline Total cholesterol (mg/dl) & $169.89 \pm 31.15$ & $173.18 \pm 37.46$ \\
\hline LDL cholesterol (mg/dl) & $105.43 \pm 22.16$ & $89.78 \pm 36.92$ \\
\hline HDL cholesterol (mg/dl) & $62.17 \pm 13.95$ & $59.00 \pm 14.98$ \\
\hline Ghrelin (pg/ml) & $1648.95 \pm 657.60^{\mathrm{d}}$ & $1005.64 \pm 640.44^{\mathrm{d}}$ \\
\hline Leptin (ng/ml) & $9.82 \pm 8.20$ & $16.06 \pm 13.93$ \\
\hline Adiponectin (ng/ml) & $23.72 \pm 6.3^{\mathrm{d}}$ & $15.06 \pm 6.18^{\mathrm{d}}$ \\
\hline Resistin (ng/ml) & $8.70 \pm 2.51$ & $10.11 \pm 3.18$ \\
\hline Glucose $0^{\prime}(\mathrm{mg} / \mathrm{dl})$ & $84.86 \pm 4.49$ & $83.90 \pm 10.00$ \\
\hline Insulin $0^{\prime}(\mathrm{uIU} / \mathrm{ml})$ & $5.92 \pm 4.43^{\mathrm{d}}$ & $9.07 \pm 3.63^{\mathrm{d}}$ \\
\hline IRI HOMA & $1.36 \pm 1.04^{\mathrm{d}}$ & $1.93 \pm 0.94^{\mathrm{d}}$ \\
\hline
\end{tabular}

Data are presented as the means \pm SD. GHD: growth hormone deficiency; SDS: standard deviation score; BMI: body mass index; CA: chronological age; HA: height age; IGF-I: insulin-like growth factor I; IGFBP-3: insulin-like growth factor binding protein 3; LDL-cholesterol: low density lipoprotein-cholesterol; HDL-cholesterol: high density lipoprotein-cholesterol; IRI HOMA: insulin resistance index according to homeostasis model assessment. In the individual rows of the table, the variables designated with the same letters differ significantly from each other with ${ }^{\mathrm{a}} p<0.0005,{ }^{\mathrm{b}} p<0.005,{ }^{\mathrm{c}} p<0.01$, and ${ }^{\mathrm{d}} p<0.05$. One-way analysis of variance (ANOVA) was used for group comparison.

Therefore, in children with GH deficiency and an excess of ghrelin secretion, a tendency towards metabolic disorders should be suspected. In contrast, in the group of children with GHD and higher ghrelin concentration that we analysed, the metabolic profile was better than in children with GHD and lower ghrelin concentration.

Further, it seems that ghrelin is not the cause of obesity or leanness, but rather one aspect of a compensatory mechanism that maintains body energy homeostasis [40]. The diet-induced obesity suppressed the neuroendocrine ghrelin system by decreasing ghrelin production in the stomach, as well as by ghrelin resistance in arcuate neuropeptide Y/Agouti-related peptide (NPY/AgRP) neurons [41]. It was proved that in obese patients, ghrelin concentration is reduced, while in patients with anorexia nervosa or malnourished subjects, it was increased [42]. On the other hand, the GH receptor deficiency blunts the stimulatory effect of ghrelin on feeding and lipid production in mice [43]. It appears that in GHD children with lower IGF-I secretion and higher ghrelin production, the ghrelin effect on lipids may also be disturbed. As regards insulin, it is well known that the high circulating ghrelin level is associated with lower insulin resistance in the general population and exogenously infused ghrelin reduces insulin secretion in healthy humans [44]. The lower insulin concentration and lower IRI HOMA in GHD children with higher ghrelin were also observed by us in the present study.

In turn, as regards adiponectin, its concentration was elevated in the GHD group when we compared it to the controls. However, among children from the GHD group, the higher adiponectin concentration was observed in those with lower IGF-I bioavailability than in those with higher IGF-I bioavailability. It is well known that adiponectin has a beneficial effect on the metabolic profile in children and adults $[20,22]$. Adiponectin directly induces GH secretion from somatotropes [45]. Previously, Oliviera et al. [22] have documented high adiponectin levels in GHRH resistance patients with GHD and very low IGF-I. The authors suggested that high adiponectin production could be a compensatory mechanism to the lack of GHRH action. Also in GH receptor-deficient mice, an elevated adiponectin levels were observed [46]. Regardless of the mechanism by which 
adiponectin is increased in our GHD-low-IGF-I group, it is possible that the better metabolic profile is mainly related to higher adiponectin levels.

As regards leptin and resistin, we found a significantly higher level of leptin and lower of resistin in children with GHD in comparison to controls. However, after dividing the GHD group into subgroups, distinguished on the basis of IGF-I bioavailability, we did not find significant differences between them. It has been showed that both leptin and resistin concentrations are not important for differences in the metabolic profile observed in both subgroups of GHD children.

Summing up, GHD children are a heterogeneous group as regards pathogenesis of the diseases. Differences in bioavailability of IGF-I cause the alter secretion of ghrelin and adiponectin which probably determines the differences in the metabolic profile of GHD patients. However, further studies are necessary to explain the relationships among ghrelin, adiponectin, GH/IGF-I secretion, and orexigenic axis action. The effect is probably related to the overlapping of several elements.

The purpose of our considerations was not to overturn the thesis that GH treatment in GHD (which obviously results in an increase of IGF-I concentration) does improve metabolic processes. The metabolic benefits of $\mathrm{GH}$ therapy, both in adults and in children, are undeniable. The aim of our study was to present the different possible variants of GHD in children before treatment, resulting from different etiology of disease, or a coexistence of disorders overlapping GHD.

\section{Conclusion}

In GHD children, the metabolic profile is related to IGF-I bioavailability and nutritional status, as well as ghrelin and adiponectin production. In GHD children in whom the lower bioavailability of IGF-I is observed, the better metabolic profile is noted. The lower the IGF-I bioavailability, the better metabolic profile is observed. It may depend on higher adiponectin related to good insulin sensitivity; however, unfavourable effects of ghrelin action on lipids were not observed by us.

\section{Conflicts of Interest}

None of the authors have any potential conflicts of interest associated with this research.

\section{Acknowledgments}

The study was supported by the Ministry of Scientific Research and Information Technology (Project no. 2 P05E 01030).

\section{References}

[1] N. Møller and J. O. Jørgensen, "Effects of growth hormone on glucose, lipid, and protein metabolism in human subjects," Endocrine Review, vol. 30, no. 2, pp. 152-177, 2009.
[2] A. Vijayakumar, R. Novosyadlyy, Y. Wu, S. Yakar, and D. LeRoith, "Biological effects of growth hormone on carbohydrate and lipid metabolism," Growth Hormone \& IGF Research, vol. 20, no. 1, pp. 1-7, 2010.

[3] V. E. Chaves, F. M. Júnior, and G. L. Bertolini, "The metabolic effects of growth hormone in adipose tissue," Endocrine, vol. 44, no. 2, pp. 293-302, 2013.

[4] H. Gleeson, E. S. Barreto, R. Salvatori et al., "Metabolic effects of growth hormone $(\mathrm{GH})$ replacement in children and adolescents with severe isolated GH deficiency due to a GHRH receptor mutation," Clinical Endocrinology (Oxford), vol. 66, no. 4, pp. 466-474, 2007.

[5] D. Capalbo, R. G. Mattace, A. Esposito et al., "Cluster of cardiometabolic risk factors in children with GH deficiency: a prospective, case-control study," Clinical Endocrinology (Oxford), vol. 80, no. 6, pp. 856-862, 2014.

[6] A. Ciresi, M. C. Amato, A. Criscimanna et al., "Metabolic parameters and adipokine profile during $\mathrm{GH}$ replacement therapy in children with GH deficiency," European Journal of Endocrinology, vol. 156, no. 3, pp. 353-360, 2007.

[7] J. P. López-Siguero, L. F. López-Canti, R. Espino et al., "Effect of recombinant growth hormone on leptin, adiponectin, resistin, interleukin-6, tumor necrosis factor- $\alpha$ and ghrelin levels in growth hormone-deficient children," Journal of Endocrinological Investigation, vol. 34, no. 4, pp. 300-306, 2011.

[8] C. Meazza, H. H. Elsedfy, S. Pagani, E. Bozzola, M. El Kholy, and M. Bozzola, "Metabolic parameters and adipokine profile in growth hormone deficient (GHD) children before and after 12-month GH treatment," Hormone \& Metabolic Research, vol. 46, no. 3, pp. 219-223, 2014.

[9] A. Juul, P. Dalgaard, W. F. Blum et al., "Serum levels of insulinlike growth factor (IGF) binding protein 3 (IGFBP-3) in healthy infants, children and adolescents: the relation to IGFI, IGF-II, IGFBP-1, IGFBP-2, age, sex, body mass index, and pubertal maturation," Journal of Clinical Endocrinology and Metabolism, vol. 80, no. 8, pp. 2534-2542, 1995.

[10] R. Stawerska, J. Smyczynska, E. Czkwianianc, H. Pisarek, M. Hilczer, and A. Lewinski, "Ghrelin concentration is correlated with IGF-I/IGFBP-3 molar ratio but not with GH secretion in children with short stature," Neuroendocrinology Letters, vol. 33, no. 4, pp. 412-418, 2012.

[11] R. Stawerska, J. Smyczynska, E. Czkwianianc, M. Hilczer, and A. Lewinski, "High concentration of ghrelin in children with growth hormone deficiency and neurosecretory dysfunction," Neuroendocrinology Letters, vol. 33, no. 3, pp. 331-339, 2012.

[12] M. Kojima, H. Hosoda, Y. Date, M. Nakazato, H. Matsuo, and K. Kangawa, "Ghrelin is a growth-hormone-releasing acylated peptide from stomach," Nature, vol. 402, no. 6762, pp. 656660, 1999.

[13] M. Nakazato, N. Murakami, Y. Date et al., "A role for ghrelin in the central regulation of feeding," Nature, vol. 409, no. 6817, pp. 194-198, 2001.

[14] T. Sato, Y. Nakamura, Y. Shiimura, H. Ohgusu, K. Kangawa, and M. Kojima, "Structure, regulation and function of ghrelin," The Journal of Biochemistry, vol. 151, no. 2, pp. 119-128, 2012.

[15] S. Sangiao-Alvarellos, M. J. Vázquez, L. Varela et al., "Central ghrelin regulates peripheral lipid metabolism in a growth hormone-independent fashion," Endocrinology, vol. 150, no. 10, pp. 4562-4574, 2009.

[16] C. Diéguez, K. da Boit, M. G. Novelle, P. B. Martínez de Morentin, R. Nogueiras, and M. López, "New insights in 
ghrelin orexigenic effect," in Frontiers of Hormone Research, E. Arzt, M. Bronstein, and M. Guitelman, Eds., vol. 38 of Pituitary Today II New Molecular, Physiological and Clinical Aspects, pp. 196-205, 2010.

[17] W. F. Blum, P. Englaro, S. Hanitsch et al., "Plasma leptin levels in healthy children and adolescents: dependence on body mass index, body fat mass, gender, pubertal stage, and testosterone," Journal of Clinical Endocrinology and Metabolism, vol. 82, no. 9, pp. 2904-2910, 1997.

[18] J. L. Wilson and P. J. Enriori, "A talk between fat tissue, gut, pancreas and brain to control body weight," Molecular and Cellular Endocrinology, vol. 418, Part 2, pp. 108-119, 2015.

[19] U. Meier and A. M. Gressner, "Endocrine regulation of energy metabolism: review of pathobiochemical and clinical chemical aspects of leptin, ghrelin, adiponectin, and resistin," Clinical Chemistry, vol. 50, no. 9, pp. 1511-1525, 2004.

[20] C. M. Ghantous, Z. Azrak, S. Hanache, W. Abou-Kheir, and A. Zeidan, "Differential role of leptin and adiponectin in cardiovascular system," Internationa Journal of Endocrinology, vol. 2015, Article ID 534320, p. 13, 2015.

[21] J. He, Y. Fang, X. Lin et al., "The relationship between gene polymorphism of leptin and leptin receptor and growth hormone deficiency," Medical Science Monitor, vol. 22, pp. 642646, 2016.

[22] C. R. Oliveira, R. Salvatori, R. A. Meneguz-Moreno et al., "Adipokine profile and urinary albumin excretion in isolated growth hormone deficiency," Journal of Clinical Endocrinology and Metabolism, vol. 95, no. 2, pp. 693-698, 2010.

[23] T. Yamauchi, J. Kamon, Y. Minokoshi et al., "Adiponectin stimulates glucose utilization and fatty-acid oxidation by activating AMP-activated protein kinase," Nature Medicine, vol. 8, no. 11, pp. 1288-1295, 2002.

[24] A. Ciresi, G. Pizzolanti, M. Leotta, V. Guarnotta, G. Teresi, and C. Giordano, "Resistin, visfatin, leptin and omentin are differently related to hormonal and metabolic parameters in growth hormone-deficient children," Journal of Endocrinological Investigation, vol. 39, no. 9, pp. 1023-1030, 2016.

[25] I. Palczewska and Z. Niedźwiecka, "Indices of somatic development of Warsaw children and adolescents," Medycyna Wieku Rozwojowego, vol. 5, supplement 1/2, pp. 17-118, 2001.

[26] M. W. Elmlinger, M. M. Kuhnel, M. M. Weber, and M. B. Ranke, "Reference ranges for two automated chemiluminescent assays for serum insulin-like growth factor I (IGF-I) and IGF-binding protein 3 (IGFBP-3)," Clinical Chemistry and Laboratory Medicine, vol. 42, no. 6, pp. 654-664, 2004.

[27] D. R. Matthews, J. P. Hosker, A. S. Rudenski, B. A. Naylor, D. F. Treacher, and R. C. Turner, "Homeostasis model assessment: insulin resistance and beta-cell function from fasting plasma glucose and insulin concentrations in man," Diabetologia, vol. 28, no. 7, pp. 412-419, 1985.

[28] M. Elbornsson, G. Götherström, I. Bosæus, B. Å. Bengtsson, G. Johannsson, and J. Svensson, "Fifteen years of GH replacement improves body composition and cardiovascular risk factors," European Journal of Endocrinology, vol. 168, no. 5, pp. 745-753, 2013.

[29] A. Ciresi, S. Radellini, V. Guarnotta, and C. Giordano, "The visceral adiposity index is associated with insulin sensitivity and IGF-I levels in adults with growth hormone deficiency," Endocrine, 2016.

[30] B. P. Hauffa, N. Lehmann, M. Bettendorf et al., "Central laboratory reassessment of IGF-I, IGF-binding protein-3, and GH serum concentrations measured at local treatment centers in growth-impaired children: implications for the agreement between outpatient screening and the results of somatotropic axis functional testing," European Journal of Endocrinology, vol. 157, no. 5, pp. 597-603, 2007.

[31] M. E. Molitch, D. R. Clemmons, S. Malozowski, G. R. Merriam, and M. L. Vance, "Evaluation and treatment of adult growth hormone deficiency: an Endocrine Society clinical practice guideline," Journal of Clinical Endocrinology and Metabolism, vol. 96, no. 6, pp. 1587-1609, 2011.

[32] C. Dieguez and F. F. Casanueva, "Influence of metabolic substrates and obesity on growth hormone secretion," Trends in Endocrinology and Metabolism, vol. 6, no. 2, pp. 55-59, 1995.

[33] F. Cordido, J. Garcia-Buela, S. Sangiao-Alvarellos, T. Martinez, and O. Vidal, "The decreased growth hormone response to growth hormone releasing hormone in obesity is associated to cardiometabolic risk factors," Mediators of Inflammation, vol. 2010, Article ID 434562, p. 8, 2010.

[34] P. Alvarez-Castro, M. L. Isidro, J. Garcia-Buela et al., "Marked GH secretion after ghrelin alone or combined with GH-releasing hormone (GHRH) in obese patients," Clinical Endocrinology (Oxford), vol. 61, no. 2, pp. 250-255, 2004.

[35] G. Corneli, C. Di Somma, R. Baldelli et al., "The cut-off limits of the GH response to GH-releasing hormone-arginine test related to body mass index," European Journal of Endocrinology, vol. 153, no. 2, pp. 257-264, 2005.

[36] N. Glynn and A. Agha, "Diagnosing growth hormone deficiency in adults," International Journal of Endocrinology, vol. 2012, Article ID 972617, p. 7, 2012.

[37] M. Tschop, D. L. Smiley, and M. L. Heiman, "Ghrelin induces adiposity in rodents," Nature, vol. 407, no. 6806, pp. 908-913, 2000.

[38] K. Dezaki, "Ghrelin function in insulin release and glucose metabolism," in The Ghrelin System, A. Benso, F. F. Casanueva, E. Ghigo and R. Granata, Eds., pp. 135-143, Karger, Basel, 2013.

[39] J. Tong, R. L. Prigeon, H. W. Davis et al., "Ghrelin suppresses glucose-stimulated insulin secretion and deteriorates glucose tolerance in healthy humans," Diabetes, vol. 59, no. 9, pp. 2145-2151, 2010.

[40] H. Iwakura, K. Kangawa, and K. Nakao, "The regulation of circulating ghrelin - with recent updates from cell-based assays," Endocrine Journal, vol. 62, no. 2, pp. 107-122, 2015.

[41] D. I. Briggs, P. J. Enriori, M. B. Lemus, M. A. Cowley, and Z. B. Andrews, "Diet-induced obesity causes ghrelin resistance in arcuate NPY/AgRP neurons," Endocrinology, vol. 151, no. 10, pp. 4745-4755, 2010.

[42] S. Solomou and M. Korbonits, "The role of ghrelin in weight-regulation disorders: implications in clinical practice," Hormones (Athens, Greece), vol. 13, no. 4, pp. 458-475, 2014.

[43] S. Sangiao-Alvarellos and F. Cordido, "Effect of ghrelin on glucose-insulin homeostasis: Therapeutic Implications International," Journal of Peptides, vol. 2010, Article ID 234709, p. 25,2010 .

[44] E. Egecioglu, M. Bjursell, A. Ljungberg et al., "Growth hormone receptor deficiency results in blunted ghrelin feeding response, obesity, and hypolipidemia in mice," American Journal of Physiology - Endocrinology and Metabolism, vol. 290, no. 2, Article ID 16174655, pp. 317-325, 2006. 
[45] F. J. Steyn, F. Boehme, E. Vargas et al., "Adiponectin regulates growth hormone secretion via adiponectin receptor mediated $\mathrm{Ca} 2+$ signaling in rat somatotrophs in vitro," Journal of Neuroendocrinology, vol. 21, no. 8, pp. 698-704, 2009.

[46] L. Nilsson, N. Binart, M. Bohlooly-Y et al., "Prolactin and growth hormone regulate adiponectin secretion and receptor expression in adipose tissue," Biochemical and Biophysical Research Communications, vol. 331, no. 4, pp. 1120-1126, 2005. 


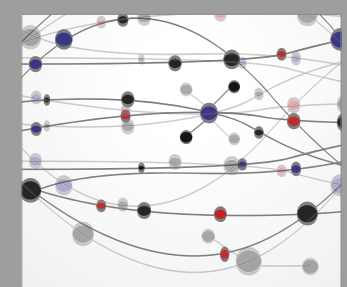

The Scientific World Journal
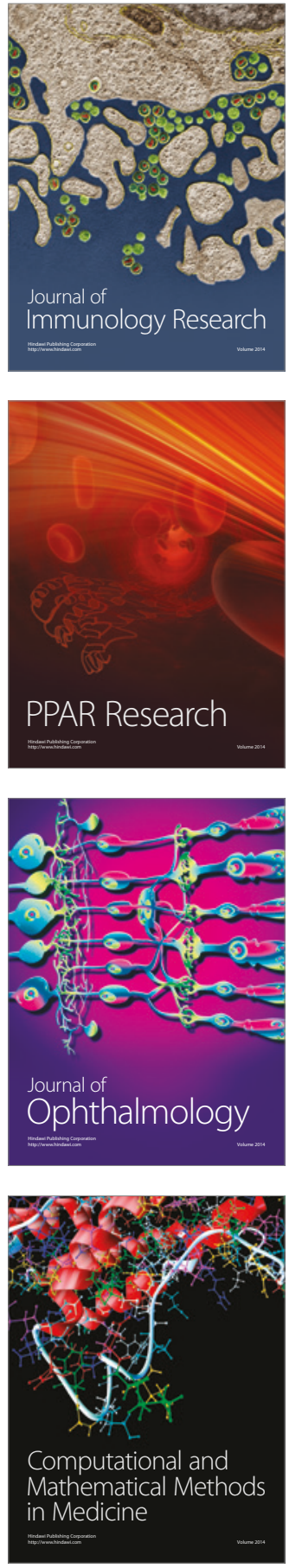

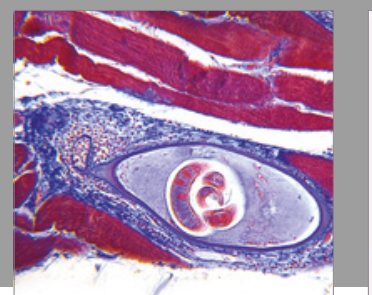

Gastroenterology Research and Practice
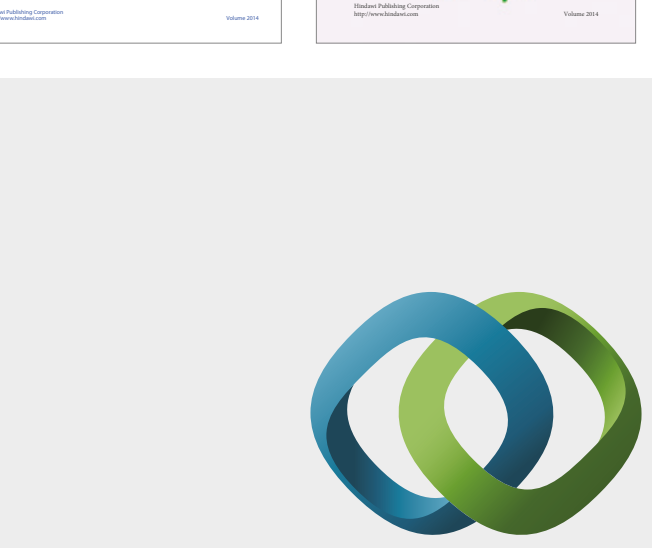

\section{Hindawi}

Submit your manuscripts at

https://www.hindawi.com
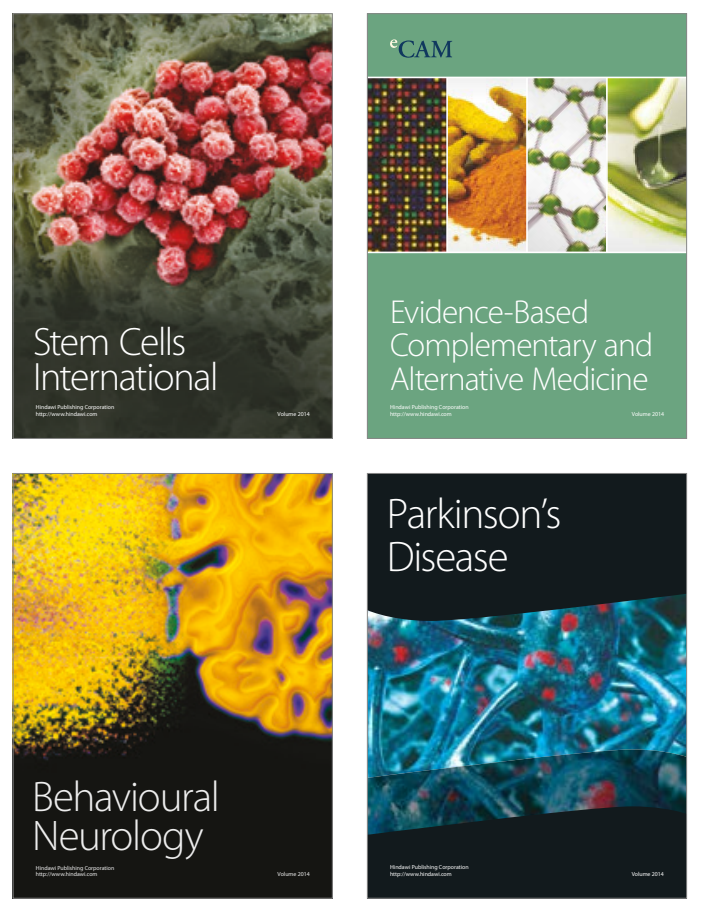
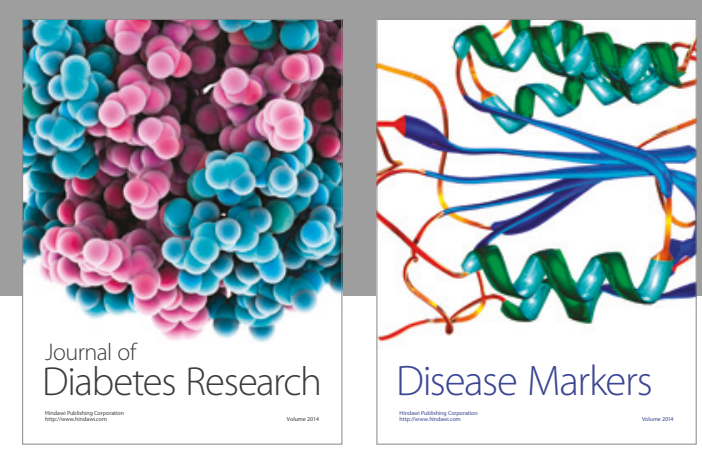

Disease Markers
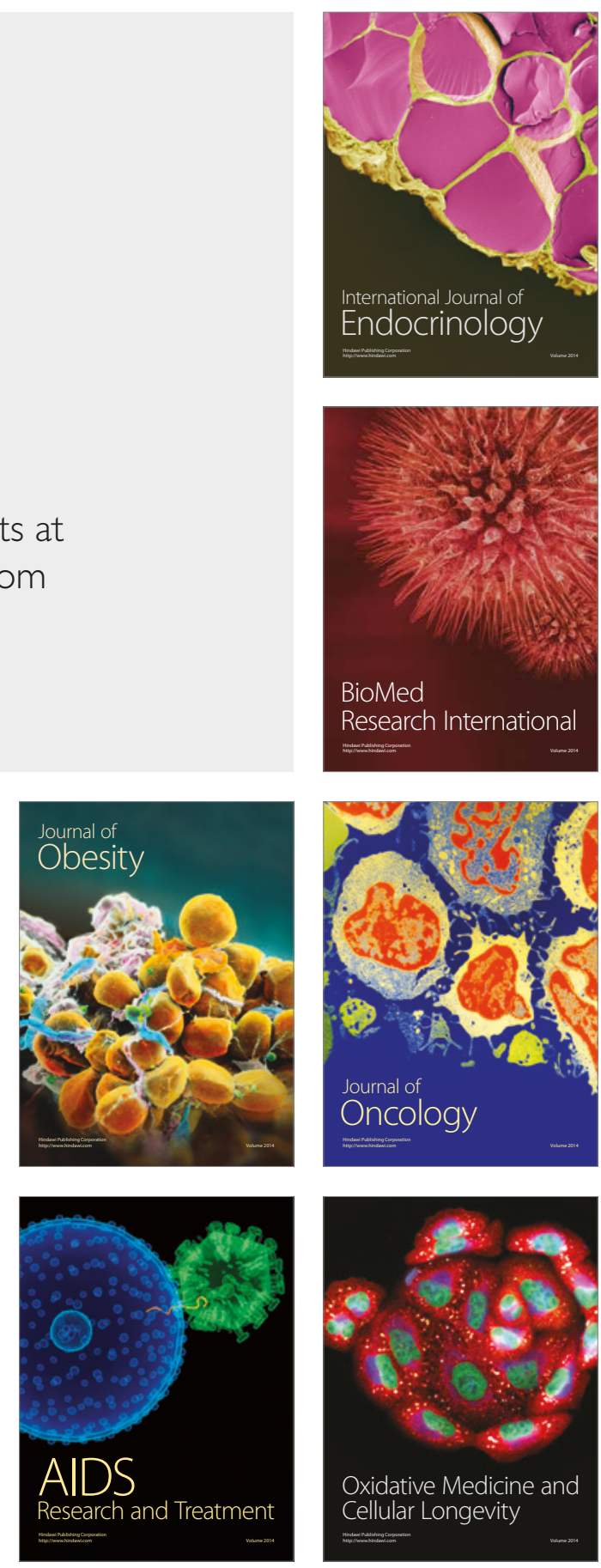